\title{
The Only Possible Mirror Image of Interpreting by Means of Understanding in Modern Western Philosophy*
}

\begin{abstract}
REN Rui
Northeastern University, Shenyang, China

Interpreting is one of the studies that is in the phase of its theoretical bottleneck. The difficulty comes from the lack of a possible holistic understanding of the phenomenon of interpreting, not to mention the mirror image of interpreting. Different linguistic studies could do nothing since nowadays their respective studies are mostly suffering their own research bottlenecks. Furthermore, it is impossible for individual linguistic studies to elaborate on the complicated interpreting practice. The only possible mirror is Modern Western Philosophy, which can present the image of interpreting. Such a mirror image is by no means possible without the full-fledged development of language study, and in particular, the uncovering of human understanding, in Modern Western Philosophy.
\end{abstract}

Keywords: mirror, image, interpreting, Modern Western Philosophy

\section{Introduction}

Interpreting is a kind of language activity which is in great need in cross-cultural communication. Interpreting practice is still in the phase of tentative probe by interpreting practioners and interpreting trainees, though interpreting skills' description and training are well-developed. Seemingly, interpreting is glorious since in simultaneous interpreting, audience can get information fast and almost at the same speed with the speaker, while in consecutive interpreting, the skill of note-taking could make interpretation long enough, which makes laymen stunned and startled. However, the state of interpreting studies is a big red apple with holes in the core. Interpreters are baffled by many realistic problems, among which interpreters' professional identity is the most tricky problem, since interpreting practioners and interpreting trainers have series of doubts about the role of interpreter, and how to deal with pairs of hauting problems of translatability/untranslatability, visibility/invisibility of interpreters, and neutrality/tendency, and so on (REN, 2014). Modern Western Philosophy could present the full image of interpreting, which acts as the mirror for the clear reflection of interpreting. Such a mirror image is by no means possible without the full-fledged development of language studies. Many modern western philosophers have contributed, for example, Friedrich Schleiermacher, Wilhelm Dilthey, Martin Heidegger, and Hans-Georg Gadamer .

\footnotetext{
* Acknowledgements: This research is funded by Education Department, Liaoning Province, China. Project of Humanities and Social Sciences (No. W2012038) is headed by REN Rui.

REN Rui, associate professor, master, English Department, Northeastern University. Doctor candidate of Foreign Philosophy at School of Philosophy and Society, Jilin University.
} 


\section{Mirror Image, Understanding and Modern Western Philosophy}

The analogy of mirror image was utilized by Gadamer (1989) in his Truth and Method, since the word speculation "refers to the mirror relation" (Gadamer, 1989, p. 465) and it is said to recall "speculum", the Latin word for mirror. Gadamer furthers the notion of mirror image as follows: Being reflected involves a constant substitution of one thing for another. When something is reflected in something else, say, the castle in the lake, it means that the lake tnrows back the image of the castle. The mirror image is essentially connected with the actual sight of the thing through the medium of the observed. It has no being of its own; it is like an "appearance" that is not itself and yet allows the thing to appear by means of a mirror image. The real mystery of a reflection is the intangibility of the image, the sheer reproduction hovering before the mind's eye (Gadamer, 1989, p. 466). The mirror image of interpreting by Modern Western Philosophy is used as an analogy to refer to the study of interpreting in the lake of Modern Western Philosophy.

Understanding is the most important act in interpreting, though in interpreting the formal word comprehension is used instead. According to the sequential model, intepreting is composed of two sequential phases: comprehension and reformulation (Gile, 1995, p. 75). In interpreting, comprehension refers to the understanding of message in both the source and target languages. Reformulating means to convey the message in the target language. Comparatively, comprehension is complex and more delicate since reformulating is the production of comprehension. Definitions given to comprehension and understanding by Longman Dictionary of Contemporary English (New Edition) (1993) are: comprehension, fml (formal word), meaning "the act of understanding or ability to understand" (p. 206); understanding, meaning "ability to know and learn", "knowledge of the nature of something, based esp. on learning or experinece" and "the way in which one judges the meaning of something" (p. 1152). Obviously, by definition, understanding covers a wider range of things than comprehension. As far as the mirror imgage of interpreting is concerned, the term understanding is utilized over comprehension in depicting a philosophical picture of interpreting.

In the wide covery of Modern Western Philosophy refering to 20th-century philosophy that,

Saw the development of a number of new philosophical schools including logical positivism, analytic philosophy, phenomenology, existentialism and poststructuralism. In terms of the eras of philosophy, it is usually labeled as contemporary philosophy...succeeding modern philosophy which runs roughly from the time of Descartes until the twentieth-century. ${ }^{1}$

This period of philosophies is more and more human and pragmatic in explaining human existence, understanding, and language. It witnessed the development of "analytic philosophy" and "continental philosophy", with the latter referring to "a set of traditions of 19th and 20th century philosophy from mainland Europe". "Phenomenology, existentialism, and hermeneutics" are among the many movements included by Continental philosophy. ${ }^{3}$ The philosophy of understanding became one of the most attrative part in modern western philsophy. Understanding moved to the position of ontology (Gadamer, 1989).

\footnotetext{
${ }^{1}$ See https://en.wikipedia.org/wiki/20th-century_philosophy.

2 See https://en.wikipedia.org/wiki/20th-century_philosophy.

${ }^{3}$ See https://en.wikipedia.org/wiki/Continental_philosophy.
} 


\section{Traditional Interpreting Studies}

Interpreting is thought to be one of the oldest professions in the world originating from the very beginning of cross-language communication when two tribes speaking two langauges was concerned. Yet, the study of interpreting is far beyond being satisfied by the people who are doing interpreting and research interpreting.

Interpreting is miraculous to laymen and vague to practitioners even, since everything involved is inside interpreters' minds which make the description of the activity of interpreting itself difficult. Code of ethics in interpreting and principles followed by practitioners are summed up according to the common sense, which explains the development of interpreter's role being from "a passive conduit" to a "mediator" (SU, 2010) and to "an active controller" (REN, 2010, p. 540). Undoubtedly, Daniel Gile presented the most classical panorama of interpreting in his book Basic Concepts and Models for Interpreter and Translator Training (1995), ranging from models of interpreting to interpreting strategies, from interpreting phases of comprehension and reformulation to knowledge acquisition in preparing to be a good interpreter. Although the book was panoramic, it is difficult to depict interpreting and point out what can be done or what can not in interpreting, since it is vague to decide what is right or wrong. For instance, seemingly, fidelity in conveying messages is sure to be right. However, if cultural taboos were involved, literal interpretation would be avoided. In such a case, messages might be replaced by the corresponding expression in the target language in terms of culture. Then, can we say fidelity is not followed as a principle?

The fact is that researchers might have turned to different studies of linguistics to have a clear image of interpreting, but the studying of interperting multi-discipliarily is still in the exploration phase (SHUAI, 2007; ZHANG, 2012; XU, 2012). Possible reasons lie in the complexity of interpreting which can not be solved by one discipline of linguisitcs, while it is also very difficult to have researchers who are both good at interpeting practice and all disciplines of linguistics.

The most common case of interpreting studies is that the interpreting practitioner "who is busy with interpreting does not have enough time" and capacity to study interpreting and is able to present a full image of interpreting (XIAO, 2002). According to CAO and LIU, there have been three problems in interpreting research in China from the late 90 s of 20 th century to the early 21 st century. To be specific, "first, the interpreting research is not wide and deep enough". "Questions have not been explored essentially and explained fully on the account of simple, micro and narrow analysis". "Second, research methods are simple and repetitive research has been done by means of borrowing second-hand research results from each other". And "the third, being prescriptive rather than descriptive of the research is still very common" (CAO \& LIU, 2009, pp. 101-105). What is common in most studies is that a certain theory or several theories are oft-used in the analysis of different interpretation types, prescriptive evaluation is ususally given in the same way(s). And common modes are followed.

The complexity of interpreting complicates the matter. As a matter of fact, there is no mirror of interperting in the current interpreting studies. What has been proven by traditional interpreting studies is that what could be fulfilled easily are things like the technical picture of the act of interpreting by Gile (1995) and the prescriptive code and regulations prescribed by organizations, like that of Australian Institute of Interpreters and Translators (in short, AUSIT) (2012). There has not been any possible mirror image of interpreting in the fields of interpreting and linguistics. 


\section{Understanding: The Intersection of Interpreting and Philosophy}

For interpreters, first and foremost, understanding is the first encounter he/she has to confront. In communication, what is commonly taken for granted is understanding, and misunderstanding is seldom and accidental. The fact turns out to be the opposite and misunderstanding happens in both cross-cultural communication and communication by speakers of one language (REN, 2006, p. 449). Understanding has long been studied by modern western philsoophers.

Having devoted to "the art of understanding" (Schleiermacher, 1978, p. 1), Schleiermacher thinks "misunderstanding is more common and natural", which trigers him to define "hermeneutics as the art of avoiding misunderstanding" and "every problem of interpretation is a problem of understanding (Schleiermacher, 1978, p. 58). In Schleiermacher's view, there are differences between author (of a text) and interpreter in terms of time, language, history, and environment, which result in misunderstandings. Such misunderstandings not only appear in text translation but also in conversations in daily life. Hermeneutics as the art of avoiding misunderstanding, wherever there is misunderstanding, there should be hermeneutics. He categorizes two types of hermeneutical practices. One is in the strict sense, and the other is in the loose sense. Hermeneutics in the strict sense means misunderstanding occurring naturally and on every point accurate understanding should be probed and searched for. Hermeneutics in the loose sense refers to understanding occurs naturally (Schleiermacher, 1978, pp. 58-60). In interpreting biblical or classical texts, he took "reading a text" as "a discourse between the interpreter and the text itself" and "the text as the means by which the author is communicating thoughts previous to the creation of the text" (Schleiermacher, 1978, pp. 2-3). By the author's final production of "the text", "inner thoughts" of the author finally changed into "outer expression" in language "at the moment of text creation" (Schleiermacher, 1978, pp. 2-3).

Dilthey's understanding is closely related to experience, and "we understand individuals by means of their affinities, their commonalities. This process presupposes the connection between the universally human and individuation. On the basis of what is universal, we can see individuation extended to the manifoldness of human existence" (Dilthey, 2002, pp. 233-234). Dilthey clarified understanding in terms of human existence and individuation.

Heidegger associated understanding with his Dasein in his Being and Time (1962), but he did not deepen his idea (Heidegger, 1962, p. 182). It was Gadamer who uncovered "the nature of human understanding" and established the position of philosophical hermeneutics in Modern Western Philosophy by his work of Truth and Method (1989). In his book, Gadamer (1989) examined in detail how understanding of texts, artwork, or experience, was possible, though he claimed clearly, "My real concern was and is philosophic: not what we do or what we ought to do, but what happens to us over and above our wanting and doing" (Gadamer, 1989, p. XXVIII).

According to Palmer (1969), Schleiermacher and Dilthey "believed that meaning, as an object, could be found within a text through a particular process that allowed for a connection with the author's thoughts that led to the creation of a text" (Schleiermacher, 1978, pp. 5-10), or "the situation that led to an expression of human inner life" (Palmer, 1969, p. 98), while Gadamer thought "meaning and understanding are not objects to be found through certain methods, but are inevitable phenomena" (Palmer, 1969, p. 163). Hermeneutics is "a 
philosophical effort to account for understanding as an ontological — the ontological - process of man" (Palmer, 1969, p. 163). In a word, in discussing understanding of text, Schleiermacher (1978) and Dilthey (2002) stressed human creation and experience, while Gadamer (1989) emphasized linguisticality, dialogue, time, historicity, and fusion of horizons in understanding and dialogues are possible since it is mainly due to the harmony between speakers, the constant subject matter of a conversation, and the truth in the world.

\section{The Mirror Image: Philosophically Clarified Interpreting Practice}

Human feelings in both translation and interpreting play an important role. Humanness is a tricky problem in understanding and interpreting. Interpreting is a complex activity involving man. Interpreting is largely influenced and determined by traits of human understanding involving "otherness", "certainty", and "uncertainty" (REN, 2014). Humanness and man decides the features of interpreting and makes its mirror image in philosophy.

Since linguistic understanding has the features of otherness and uncertainty, it might lead to misunderstanding in interpreting. Similar to what has been discussed by Schleiermacher, in interpreting, interpreter undergoes the same thing with that of interpreter of a text, the inner thoughts of the speaker and the source language that $\mathrm{s} /$ he uses in producing the speech should be understood in the right way. Together with the interpreter of a text, interpreter of a speech also goes for "the ultimate goal" of "understanding in the highest sense" (Schleiermacher, 1998, p. 228). In interpreting, the relationship of the interpreter of a speech to the source language is "cyclical", both the speaker and interpreter are limited by their "language and historical context" (Schleiermacher, 1978, pp. 5, 10).The interpreter must understand how the "original audience understood this language" (Schleiermacher, 1978, p. 6), namely how native audience understand the speaker's source language, then correct interpretation into the target language could be possible.

It was Schleiermacher and Dilthey who clarified understanding and interpreting as human action and existence, i.e., that of speaker, interpreter, and audience.

Heidegger put forward Dasein or "being-in-the-world" in his Being and Time (1962), understanding was depicted as "being-there as understanding". "State-of-mind is one of the existential structures in which the Being of the 'there' maintains itself". "If we interpret understanding as a fundamental existentiale, this indicates that this phenomenon is conceived as a basic mode of Dasein's Being" (Heidegger, 1962, p. 182). The ontological position of understanding was established.

Gadamer furthered Heidegger's theory and a mature philospophical hermeneutics came into being. Gadamer (1989) has given the mirror image of interpreting in his book, though often together with translation. People living in the world might speak different languages, but they live in the world with the "subject matter" to whatever degree (Gadamer, 1989, p. 180). There are things in common, which guarantee understanding and interpreting possible.

Language is the medium in which substantive understanding and agreement take place between two persons. In situations where coming to an understanding is disrupted or impeded, we first become conscious of the conditions of all understanding. Thus the verbal process whereby a conversation in two different languages is made possible through translation is especially informative. Here the translator must translate the meaning to be understood into the context in which the other speaker lives. This does not, of course, mean that he is at liberty to falsify the meaning of what the other person says. Rather, the meaning must be preserved, but since it must be understood within a new language world, it must 
establish its validity within it in a new way. Thus every translation is at the same time an interpretation. (Gadamer, 1989, p. 386)

Every language can be learned so perfectly that using it no longer means translating from or into one's native tongue, but thinking in the foreign language. Mastering the language is a necessary precondition for coming to an understanding in a conversation. Every conversation obviously presupposes that the two speakers speak the same language. Only when two people can make themselves understood through language by talking together can the problem of understanding and agreement even be raised. Having to depend on an interpreter's translation is an extreme case that doubles the hermeneutical process, namely the conversation: There is one conversation between the interpreter and the other, and a second between the interpreter and oneself. (Gadamer, 1989, p. 387)

Otherness of understanding is made clear by the following statement by Gadamer,

Understanding becomes a special task only when natural life, this joint meaning of the meant where both intend a common subject matter, is disturbed. Where misunderstandings have arisen or where an expression of opinion alienates us because it is unintelligible, there natural life in the subject matter intended is impeded in such a way that the meaning is given as the opinion of another, the opinion of the Thou or of the text, or in general as a fixed datum. And even then in general one attempts to reach a substantive agreement—not just sympathetic understanding of the other person-and this in such a way that again one proceeds via the subject matter. Only if all these movements comprising the art of conversation - argument, question and answer, objection and refutation, which are undertaken in regard to a text as an inner dialogue of the soul seeking understanding - are in vain is the inquiry detoured. Only then does the effort of understanding become aware of the individuality of the Thou and take account of his uniqueness. (Gadamer, 1989, p. 181)

Spinoza clarified the historicity of interpreting,

Spinoza elaborates his method of interpreting Scripture by analogy to the interpretation of nature: we have to derive the meaning (mens) of the authors from historical data, since things are related in these books (stories of miracles and revelations) that cannot be derived from the principles known to us by natural reason. Independently of the fact that Scripture on the whole undoubtedly has a moral significance, in these matters which are, in themselves, incomprehensible (imperceptibiles), everything important can be understood if only we understand the mind of the author "historically"-i.e., overcome our prejudices and think of nothing but what the author could have had in mind. (Gadamer, 1989, p.181)

Due to otherness and historicity, interpreting is undoubtedly recreation by interpreter on the basis of his own individuality. Such recreation is just approximation approaching faithfulness, but never a complete faithful interpretation. Just like what Gadamer mentioned in his book, though difficult decisions they might be.

Let us again start by considering the extreme case of translation from a foreign language. Here no one can doubt that the translation of a text, however much the translator may have dwelt with and empathized with his author, cannot be simply a re-awakening of the original process in the writer's mind; rather, it is necessarily a re-creation of the text guided by the way the translator understands what it says. No one can doubt that what we are dealing with here is interpretation, and not simply reproduction. A new light falls on the text from the other language and for the reader of it. The requirement that a translation be faithful cannot remove the fundamental gulf between the two languages. However faithful we try to be, we have to make difficult decisions. (Gadamer, 1989, p. 387)

And all the time interpreter and translator are fully tortured by his/her complete awareness.

The translator is often painfully aware of his inevitable distance from the original. His dealing with the text is like the effort to come to an understanding in conversation. But translating is like an especially laborious process of understanding, in which one views the distance between one's own opinion and its contrary as ultimately unbridgeable. (Gadamer, 1989, p. 388) 
On the basis of what has been discussed above, the mirror image of interpreting in Modern Western Philosophy could be summed up as follows: Interpreting is an open activity that speaker, interpreter, and audience in their own being in the world are constantly dynamic though they are restricted by their language, culture, environment, experience, habits, and prejudices, which also lead to their dynamism in terms of time and history. The first and most striking feature of interpreting is otherness. In the interpreted communication event (ICE) (Angelelli, 2004, p. 8) of interpreting, due to the existence of the other and individuality of persons involved, understanding or agreement in receiving messages in the target language is bound by otherness. Otherness involved in interpreting also leads to uncertainty of interpreting since audience might reach the agreement with the interpreter in understanding messages conveyed by the speaker in the source language. However, what occupies the same percentage of chances or odds is that they audience might not agree with the interpreter in terms of understanding messages in the source language. So, uncertainty is the second striking feature of interpreting. Lastly, the third feature, certainty of interpreting, is for sure owing to the common subject matter people share in the world. Though this certainty, as a matter of fact, is the approximation of interpreting that interpreter endeavors to shorten the distance between reality of the source and his/her understanding, namely, when encountered the extreme case of untranslatable interpreting tasks, interpreting still has to be done and fulfilled for the time (REN, 2014, p. 117).

\section{Conclusion}

As far as interpreting is concerned, still there is much to be researched on. Nowadays, the image of interpreting could be obtained on the basis of philosophical studies of understanding in Modern Western Philosophy. Otherness, uncertainty and certainty are features of interpreting. Since speaker, interpreter, and audience are involved in interpreting, and whether one could be understood by the other depends on the concord in understanding between self and the other. As to interpreting, interpreters need to take both speakers and audience into account linguistically, culturally, and psychologcally. Interpreting is a complicated subject, which could be elaborated by philosophy. Many modern western philosophers have researched on interpreting of texts. Although translation and interpreting differ in form, there is a lot in common in content of the two. Also, thanks to the developments in Modern Western Philosophy, the existence of language has been growingly disclosed, which suffices conditions for having a clearer and clearer mirror image of interperting.

\section{References}

20th-century philosophy. (n.d.). In Wikipedia. Retrieved from https://en.wikipedia.org/wiki/20th-century_philosophy Angelelli, C. V. (2004). Medical interpreting and cross-cultural communication. Cambridge: Cambridge University Press.

CAO, W. W., \& LIU, S. L. (2009). Research on interpreting from the late 90s of the 20th century to the early 21st century in China. Journal of Yunnan Agricultural University, 3(1), 101-105.

Code of Ethics. (2012). In Ausit. Retrieved from http://ausit.org/AUSIT/Documents/Code_Of_Ethics_Full.pdf

Continental philosophy. (n.d.). In Wikipedia. Retrieved from https://en.wikipedia.org/wiki/Continental_philosophy

Dilthey, W. (2002). Selected works. In R. A. Makkreel and F. Rodi (Eds.), The formation of the historical world in the human sciences Princeton (Vol. 3). NJ: Princeton University Press.

Gadamer, H. G. (1989). Truth and method (2nd revised ed.). (J. Weinsheimer \& D. G. Marshall, Trans.). London: Sheed and Ward.

Gile, D. (1995). Basic concepts and models for interpreter and translator training. Amsterdam \& Philadelphia: John Benjamins. Heidegger, M. (1962). Being and time. (J. Macquarrie \& E. Robinson, Trans.). Oxford: Basil Blackwell Publisher Ltd.. 
Longman dictionary of contemporary English (new ed.). (1993). London: Longman Group UK Limited.

Palmer, R. (1969). Hermeneutics: Interpretation theory in Schleiermacher, Dilthey, Heidegger, and Gadamer. Evanston, IL: Northwestern University Press.

REN, R. (2006). Analysis of understanding problems in intercultural language communication. Journal of Northeastern University (Social Science), 8(6), 449.

REN, R. (2009). On self and the other in language understanding. Journal of Northeastern University (Social Science), $11(2), 170$.

REN, R. (2010). On translator's visibility. Journal of Northeastern University (Social Science), 12(6), 540 .

REN, R. (2014). An Introduction to interpretation for graduates (Chinese ed.). Shenyang: Northeastern University Press.

Schleiermacher, F. D. E. (1978). The hermeneutics: Outline of the 1819 lectures. New Literary History, Literary Hermeneutics, $10(1), 2-3,5,6,9,10$.

Schleiermacher, F. D. E. (1998). Hermeneutics and Criticism. A. Bowie (Ed.). Cambridge, U.K.: Cambridge University Press.

SHUAI, L. (2007). Multi-disciplinary research of interpretation theory in China. Chinese Science and Technology Translators Journal, 20(3), 50-52.

SU, W. (2010). "Conduit" or "mediator": An empirical study of the role of the medical interpreter. Journal of Foreign Languages Research, 6(5), 84-88.

Wilhelm Dilthey. (n.d.). In Wikipedia. Retrieved from https://en.wikipedia.org/wiki/Wilhelm_Dilthey

XIAO, X. Y. (2002). Interpreting research in the West: a critical analysis of its history and current status. Journal of Foreign Languages, 4, 71-73.

XU, M. (2012). Interpreting abilities studies from the multi-disciplinary persepective. Foreign Language Education in China, 2 , 40-48.

ZHANG, W. (2012). Multi-disciplinary exploration of interpretation: puzzles and way-outs. Chinese Translator Journal, 3, 13-19. 